\title{
HIBRIDAÇÃO CULTURAL E GLOBALIZAÇÃO: reflexos sobre a padronização global e a criatividade.
}

\author{
Dinara Dal Pai \\ Universidade Feevale \\ dinadalpai@hotmail.com
}

\begin{abstract}
Resumo: Este artigo analisa como os encontros culturais, compreendidos como hibridação cultural, influenciam o potencial criativo das pessoas. Apesar de a criatividade ser incentivada pelo cruzamento de diferentes estímulos culturais, as hibridações resultantes dos processos de globalização e da crescente padronização do consumo afetam diretamente este potencial criativo levando à redução da diversidade criativa global e local.
\end{abstract}

Palavras-chave: hibridação cultural, globalização, criatividade, padronização do consumo.

\begin{abstract}
This article analyses how cultural encounters, understood as cultural hybridization, influence people's creative potential. Although creativity is encouraged by the intersection of different cultural stimuli, hybridizations resulting from globalization processes and increasing standardization of consumption directly affect people's creative potential, resulting in the reduction of local and global creative diversity.
\end{abstract}

Keywords: cultural hybridization, globalization, creativity, standardization of consumption.

\section{INTRODUÇÃO}

A palavra globalização representa e traduz a atual dinâmica da sociedade contemporânea, caracterizada por processos que atuam em escala global, diminuição de fronteiras e aproximação das diferentes nações. Segundo Bauman $(1999$, p.7), a definição de globalização divide opiniões, entre perspectivas positivas e negativas, mas, ao mesmo tempo, tem-se o consenso de que este fenômeno é o "destino irremediável do mundo, um processo irreversível e que afeta a todos".

Dentre os aspectos mais importantes relacionados à globalização está a nova relação entre tempo e espaço, pois sua compressão, através da evolução tecnológica, modifica a noção de distância e de escala temporal, libertando o movimento das limitações impostas pelo espaço. Bauman (2001) utiliza o termo 
"líquido" como metáfora para esse novo contexto, observando que, diferente dos sólidos, os líquidos não mantêm sua forma, nem se fixam ao espaço e ao tempo. Na visão do autor, o líquido traduz também a aceleração das mudanças que caracterizam a atualidade, enquanto que o sólido simboliza a rigidez e a inércia que caracterizaram a era industrial.

Orientada pelo sistema capitalista, a globalização carrega consigo enormes desigualdades, uma vez que nem todos participam plenamente das vantagens trazidas por este contexto líquido, fato que torna a liberdade de movimento e a extraterritorialidade um verdadeiro signo de poder (BAUMAN, 1999). Como resultado, apenas o negócio, o comércio, as finanças e o fluxo de informações tornam-se plenamente extraterritoriais e é precisamente nesse momento que se iniciam os encontros culturais e suas hibridações nas formas que mais caracterizam os atuais processos de globalização. Ao encontro desse pensamento, Canclini (2008) constata que os processos globalizadores acentuam especificamente as formas de hibridação produtiva, comunicacional e nos estilos de consumo, somando-se ainda as misturas geradas pela indústria cultural.

Nesse contexto, vinculada ao capitalismo, a globalização tem com prioridade a ampliação de mercados e para isso tende à desterritorializar empresas e ofertar bens de consumo mundialmente padronizados. De acordo com Harvey (2009, p 307), esse "processo mascara e fetichiza, alcança crescimento mediante a destruição criativa, cria novos desejos e necessidades, explora a capacidade do trabalho e do desejo humano, transforma espaços e acelera o ritmo de vida".

Tendo isso em vista, o presente artigo objetiva refletir acerca das hibridações culturais que caracterizam a acelerada globalização contemporânea. Para tanto, procurar-se-á compreender os movimentos relacionados à padronização global da produção, da informação e dos modos de consumo, bem como os seus reflexos sobre o potencial de criatividade das sociedades envolvidas nesse processo.

\section{A RELAÇÃO ENTRE GLOBALIZAÇÃO E HIBRIDAÇÃO}

O termo híbrido, original da biologia, perde sua univocidade e ganha campo de aplicação nas ciências sociais. Assim, pode-se entender por hibridação os "processos socioculturais nos quais estruturas ou práticas discretas", que existem de forma separada, se combinam para gerar novas estruturas, objetos e práticas" (CANCLINI, 2008, p.XIX). Nesse sentido, a escolha desse termo tem contribuído para identificar e explicar o seu significado de maneira metafórica.

Para Canclini (2008), o conceito de hibridação é bastante abrangente. Além de designar contatos interculturais específicos e mais ou menos clássicos como mestiçagem, sincretismo e crioulização, a hibridação abrange também formas de combinação que surgem através dos produtos das tecnologias avançadas, processos sociais modernos e pós-modernos. Dessa forma, apesar de a hibridação fazer parte de

\footnotetext{
* Segundo Canclini (2008), as estruturas chamadas discretas foram resultado de hibridização, razão pela qual não podem ser consideradas puras. Assim, o autor apresenta o "ciclo de hibridação" proposto por Brian Stross, no qual se evidencia que nenhuma forma é "pura" ou plenamente homogênea.
} 
todo desenvolvimento histórico e social, é com a globalização que se acentua o emprego desse conceito na medida em que se favorece a interculturalidade migratória, econômica e midiática por meio do desenvolvimento de novas tecnologias que modificam a relação entre tempo e espaço.

Assim, cabe destacar dois pontos fundamentais no que se refere à viabilização dos processos de hibridação na chamada sociedade da informação. O primeiro ponto refere-se à compressão tempo/espaço e à consequente modificação da noção de distância. Segundo Bauman (1999), a transformação do papel do espaço em função do tempo contempla um longo processo histórico de evolução dos meios de transporte e de comunicação que reduziram, significativamente, o tempo necessário para o contato entre diferentes culturas. No entanto, como ponto culminante dessa transformação, percebe-se que a revolução das tecnologias de informação e comunicação termina com a própria noção de viagem da informação, tornando-a instantânea em todo o planeta.

Já o segundo ponto relacionado aos processos de hibridização está ligado ao enfraquecimento do Estado-Nação que, essencialmente, baseava-se na busca pela unidade cultural e no consequente combate das diferenças étnicas. Nesse sentido, com a compressão tempo/espaço torna-se possível estabelecer uma rede de dependência mundial e o poder político é transferido para a circulação extraterritorial do capital e da informação (BAUMAN, 2003). Dessa forma,

o estado não mais preside os processos de integração social ou manejo sistêmico que faziam indispensáveis a regulação normativa, a administração da cultura e a mobilização patriótica, deixando tais tarefas (por ação ou omissão) para forças sobre as quais não tem jurisdição (BAUMAN, 2003, p. 90).

Nesse contexto, criam-se mecanismos que garantem a liberdade de movimento entre nações e a aproximação real e virtual de diferentes culturas. Segundo Bauman (1999), as distâncias perdem sua importância, ao passo que a ideia de fronteira geográfica não faz mais sentido no cenário contemporâneo.

Para Lévy (2010), o novo contexto pode ser denominado como cibercultura, sendo este um termo que traduz técnicas, práticas, atitudes e valores que são desenvolvidos juntamente com a ampliação do ciberespaço. O ciberespaço é um meio de comunicação que surge pela interconexão mundial dos computadores, ou seja, por meio da Internet. Dessa forma, sua virtualidade modifica a relação entre tempo e espaço, fazendo com que cada ponto do ciberespaço seja copresente a qualquer outro.

No entanto, cabe destacar que como resultado dos processos globalizadores, não há apenas fusões, mas também confrontações entre diferentes culturas, sendo exemplos os movimentos fundamentalistas e nacionalistas. Por outro lado, é justamente nesse sentido que "a hibridação, como processo de interseção e transações, torna possível que a multiculturalidade evite o que tem de segregação e se converta em interculturalidade" (CANCLINI, 2008, p.XXVI). Assim, as políticas de 
hibridação servem para que a história, e atualmente a globalização, não se reduzam às guerras e divergências entre culturas.

\section{PADRONIZAÇÃO}

Sabendo-se que a globalização favorece a interculturalidade global, pode-se afirmar que a hibridação é seu produto legítimo. No entanto, Bauman (1999) observa que os processos globalizadores não têm a unidade de efeitos que se supõe comumente, pois ao mesmo tempo em que o capital e o fluxo das informações adquirem dimensões globais e extraterritoriais, rompendo com as antigas noções de fronteira, a maioria da população permanece fixa ao espaço.

Tal paradoxo evidencia uma tendência de padronização global facilmente identificável, isto é, enquanto as pessoas permanecem presas ao seu território, o capital, materializado na forma de empresas e produtos, fica livre para tornar-se multinacional e inserir-se na cultura local. Da mesma forma, a informação viaja sem fronteiras e é capaz de informar localmente, por imagens, textos e som, acontecimentos de todo mundo.

Harvey (2009) descreve os reflexos desse processo ao referir-se à enorme gama de imagens vindas simultaneamente de espaços distintos, "encolhendo os espaços do mundo numa série de imagens de uma tela de televisão" (p.264). Ao mesmo tempo, o autor contribui para explicar que "a descentralização e proliferação da produção industrial termina por expor produtos Benetton e Laura Ashley nos shoppings serialmente produzidos pelo mundo capitalista" (p.267).

A revolução das tecnologias de informação e comunicação viabilizou, sobretudo, o desenvolvimento de uma economia em rede e é nesse contexto que o consumo encontra o cenário ideal para a sua expansão, enquanto que o intenso dinamismo da vida contemporânea, aliado à crescente busca pelo novo tornam o ato de consumir uma atividade básica no dia a dia de diferentes sociedadea. Diante disso, Bauman (2001) compara o consumo a uma corrida e constata que

na corrida dos consumidores, a linha de chegada sempre se move mais veloz que o mais veloz dos corredores; mas a maioria dos corredores na pista tem músculos muito flácidos e pulmões muito pequenos para correr velozmente (BAUMAN, 2001, p. 86).

Nessa metáfora, o autor evidencia a constante criação de novas necessidades de consumo como característica básica da dinâmica da economia atual. Esta dinâmica, expandida para uma escala global, propicia novas formas de hibridação mundiamente padronizadas em suas formas de produção, comunicação e nos estilos de consumo. Para Hall (2005),

os fluxos culturais, entre as nações, e o consumismo global criam possibilidades de "identidades partilhadas" - como "consumidores" para os mesmos bens, "clientes" para os mesmos serviços, "público" para as mesmas mensagens e 
imagens - entre pessoas que estão bastante distantes uma das outras no espaço e no tempo (HALL, 2005, p.74)

Tais relações deixam ainda mais claro que a lógica dos processos globalizadores está intimamente ligada à logica do sistema capitalista, essencialmente expansionista e imperialista não só no que se refere à territórios e mercados, mas também se relacionam aos setores que podem servir aos seus interesses. Assim, Harvey (2009) constata que também a cultura, num número cada vez maior de áreas, tem sua produção norteada pelo lucro, ficando ao alcance do nexo do dinheiro e da circulação extraterritorial do capital.

Com isso, a vida cultural é reorganizada para atender às demandas do consumo em massa e é nesse sentido que surge o cinema, a televisão, o rádio e as revistas. Adorno (1985) definine esse modelo como indústria cultural na medida em que a arte e transformada em negócio, como o próprio nome sugere. O mesmo autor é enfático ao afirmar que

a técnica da indústria cultural levou apenas à padronização e à produção em série, sacrificando o que fazia a diferença entre a lógica da obra e o sistema social. Isso, porém, não deve ser atribuído a nenhuma lei evolutiva da técnica enquanto tal, mas a sua função na economia atual (ADORNO, 1985, p.114)

Dessa forma, a arte adquire características de uma mercadoria que é produzida para ser consumida e, alinhando-se à lógica da globalização, tende à divulgar símbolos e valores mundialmente padronizados. Nesse sentido, ao analisar o processo de desterritorialização da cultura, Lusvarghi (2002, p.165) observa que a empresa Americana de mídias MTV Network já nasce em 1980 voltada ao mercado mundial, sendo destinada a ser "uma vitrine de consumo para as grandes marcas do segmento jovem ao redor do mundo". Assim, ao ser adquirida pela holding Viacom (terceiro maior conglomerado de mídias) chega ao território brasileiro em 1990 quando inaugura a MTV Brasil, senguindo formatos norte-americanos.

No entanto, se a globalização promove padronizações mundiais em relação à informação, produção e consumo (incluindo-se aqui os produtos da indústria cultural), por outro lado, defende-se que as hibridações resultantes desse processo não são totalmente homogêneas. Isto ocorre porque a interação com diferentes culturas necessita adaptações e transformações desses padrões. Entretanto, é evidente que esse novo contexto sociocultural afeta diretamente o potencial criativo de pessoas e nações que convivem em um mundo cada vez mais interligado e que compartilha valores e significados.

\section{CRIATIVIDADE}

Até o presente momento, está claro que, sim, a globalização envolve hibridações e essas podem resultar de formas mundialmente padronizadas de 
produção, informação e estilo de consumo. No entanto, analisam-se a partir disso quais são os fatores facilitadores e inibidores da criatividade nesse contexto de extremos encontros culturais.

Nessa perspectiva, retomando a definição de Canclini (2008), observa-se que o resultado da hibridação é o surgimento de novas estruturas, objetos e práticas. Ora, apenas a palavra "novo" já sinaliza que alguma criação acontece a partir dessa mistura, mas que tipo de criação é essa? O autor afirma que algumas vezes, a hibridação ocorre de forma imprevista e não planejada, no entanto, em muitos casos surge da criatividade individual e coletiva. Dessa forma, não apenas nas artes, mas também na vida cotidiana e no desenvolvimento tecnológico buscam-se reconverter estruturas, práticas ou objetos para reinseri-los em novas condições contextuais. Assim, retomando a análise de Lusvarghi (2002), constata-se que mesmo em situações de padronização mundial, como é o caso do canal MTV, a diversidade cultural dos paises faz com que haja adaptações no modelo original para adequa-lo ao local. Ao mesmo tempo, também a assimilação dessas mensagens pelo público ocorre de forma distista à medida que se trabalha com diferentes realidades socioculturais.

No mesmo sentido, Hall (2005) critica visões simplistas e exageradas sobre a homogeneização cultural por meio da padronização global. Para isso, apoia-se em argumentos que apontam as próprias desigualdades dos processos globalizadores e o que ele chama "fascinação com a diferença e com a mercantilização da etnia e da alteridade" (HALL, 2005, p.77) como justificativas contrárias a esse pensamento. Ao que parece, pode-se dizer que a novidade está justamente no encontro cultural que origina uma cultura híbrida, diferente das culturas que lhe deram origem.

Ao encontro desse pensamento, Castells (1999) observa que a causa da grande difusão social das inovações tecnológicas está, por um lado, na própria natureza da tecnologia, ao passo que a informação e a comunicação simbólica entre os seres humanos sempre desempenharam papel central para o desenvolvimento cultural da sociedade. Por outro lado, percebe-se que a configuração em rede, cujo símbolo é a Internet, confere à tecnologia um caráter auto-organizador que resulta do poder transformador da parte sobre o todo, ou seja, o usuário assume o poder de apropriarse da tecnologia e, ao mesmo tempo, redefini-la, recriá-la. Com isso, o próprio conhecimento, diretamente vinculado à informação, passa a ser transformado de forma contínua, uma vez que a interconexão de saberes oriundos de diferentes usuários gera um novo saber capaz de questionar tudo o que estava consolidado até então (LÉVY, 2010). Tal como Castells (1999) coloca,

as novas tecnologias da informação não são simplesmente ferramentas a serem aplicadas, mas processos a serem desenvolvidos. Usuários e criadores podem tornar-se a mesma coisa (CASTELLS, 1999, p. 69).

De acordo com Ostrower (1987, p.5), “a criatividade é um processo inerente ao homem, e a realização desse potencial uma de suas necessidades". Assim, em toda a criação, as potencialidades relativas a um ser único (ser individual) somam-se ao seu contexto cultural (ser social), fato que explicaria, respectivamente, a necessidade de reconverter e reinserir no processo de hibridação.

No entanto, segundo o autor, a atual dinâmica social tende a alterar essa 
condição humana na medida em que o homem fica sobrecarregado com múltiplas funções, pressionado por inumeras exigêncies e bombardeado por um fluxo de informações contraditórias cada vez mais aceleradas. Em consequência, pode não ocorrer a integração do ser individual com o social, mas sua desintegração, resultando em um quadro de alienação que prejudica a possibilidade de criar.

A partir dessa percepção, tem-se um paradoxo interessante a respeito do potencial criativo relacionado às atuais hibridações. Ao mesmo tempo em que se promovem interações favoráveis à criatividade, essa também é inibida por um contexto social acelerado, desarticulado e individualista. Como exemplo desse processo, Bauman (1999) observa que a informação, ao adquirir escala global e instantaneidade de transmissão, perde o vínculo com o local e tende a divulgar grande quantidade de mensagens de pouca ou nenhuma relevância em relação ao contexto. Assim, ele afirma que "a comunicação barata inunda e sufoca a memória em vez de alimentá-la e estabilizá-la" (BAUMAN, 1999, p.23).

Somando-se a isso, também as condições de padronização mundial de fatores relacionados à economia (produção e consumo) acabam alterando o potencial criativo a nível global. Harvey (2009) apresenta a teoria de Bourdieu que se torna bastante interessate ao observar as restrições do poder do imaginado sobre o vivido. Assim, ele constata que "uma matriz de percepção, avaliação e ação" (p.201) podem, a um só tempo, trabalhar de maneira flexível para realizar tarefas que são engendradas a partir da experiência material de "estruturas objetivas", isso é, a partir da base econômica da formação social em questão. Dessa forma, o nível mediador dessa produção é fornecido pelo conceito de habitus ${ }^{* *}$, sendo essa

uma capacidade infinita de engendrar produtos -
pensamentos, percepções, expressões, ações - cujos limites
são fixados pelas condições histórica e socialmente situadas de
sua produção, a liberdade condicionante e condicional que ele
garante está tão distante de uma criação de novidade
imprevisível quanto o está de uma reprodução mecânica
simples dos condicionamentos iniciais (BOURDIEU apud
HARVEY 2009, p.202).

A partir dessa análise observa-se que, se diferentes culturas possuem estruturas econômicas mundialmente padronizadas, é consequência disso a redução do potencial criativo e inovador a nível global, pois segundo essa teoria, o contexto interfere diretamente na criação. Além disso, retornando à teoria de Adorno (1985) sobre a indústria cultural, também é fato que, ao vincular-se ao capitalismo, a cultura artística como fonte de expressão e criatividade perde grande parte de seu valor ao transformar-se em mercadoria. A idéia de padronização adotada é contrária a de criação e originalidade.

${ }^{* *}$ Segundo Harvey (2009) habitual é um princípio gerativo duradouramente instalado de improvisações reguladas, que produz práticas tendentes a reproduzir as condições objetivas responsáveis pela produção do princípio gerativo de habitus. 
Para o autor, uma obra, outrora baseada em idéias, atualmente desenvolve-se com o predomínio constante de novos efeitos e detalhes técnicos que repetem sempre o mesmo esquema que garante o lucro e que é cuidadosamente controlado. Tal como o autor coloca, nada é exibido sem antes carregar traços do jargão. Assim, a indústia cultural acaba descartando o que ainda não foi experimentado por representar um risco ao mercado de consumo que já Ihe é garantido. De encontro a esse pensamento, Canclini (2008, p.63) observa que "é possível perguntar o que fariam hoje, dentro desse sistema, Leonardo, Mozart ou Baudelaire. A resposta é a que um crítico deu: Nada, a menos que eles jogassem conforme as regras".

Ainda, segundo Adorno (1985), o produto da indústria cultural inibe a atividade intelectual também do observador na medida em que tudo é antecipado no esquematismo uniforme de sua produção. Dessa forma,

a atrofia da imaginação e da espontaneidade do consumidor cultural não precisa ser reduzida a mecanismos psicológicos. Os próprios produtos - e entre eles em primeiro lugar o mais característico, filme sonoro - paralisam essa capacidade em virtude de sua própria constituição objetiva (ADORNO, 1985, p.119).

Assim, como expõe o autor, a transformação da cultura em indústria, ou seja, em negócio, torna-a refém de um sistema que visa apenas o lucro e não a qualidade artística e criativa de sua produção em massa. Contrariando toda a essência da arte, a indústria cultural inibe a criatividade de quem cria e também de quem observa.

\section{CONSIDERAÇÕES FINAIS}

A presente revisão teórica permite afirmar que a hibridação, resultante de encontros culturais viabilizados pelos processos globalizadores, carrega consigo características peculiares que afetam diretamente as estruturas locais e globais. Essa, por sua vez, é viabilizada pelo desenvolvimento tecnológico que comprime espaço/tempo fazendo surgir uma nova forma de poder: a mobilidade.

Entretanto, esse poder é assumido pelo capital e pelo fluxo de informação que se tornam plenamente extraterritoriais, fato que abala o controle exercido pelo Estado-nação sobre a unidade cultural nacional. Em consequência, sendo esse um processo orientado pela lógica do sistema capitalista, as hibridações resultantes desse encontro tendem a gerar misturas mundialmente padronizadas em suas formas de produção, consumo e comunicação, situação que faz com que nações distantes adquiram crescentes similaridades.

Nesse contexto, apesar de a criatividade ser um processo inerente ao ser humano e que pode ser potencializado pela diversidade de estímulos e referências, as atuais hibridações resultantes dos processos globalizadores e de seu contexto de padronização afetam diretamente esse potencial, trabalhando para a redução da diversidade criativa global e local na medida em que se tem uma sociedade sobrecarregada e estressada por uma economia que se volta totalmente para o lucro e para o consumo. Alinhada ao sistema capitalista, até mesmo a arte, que antes estava afavor da expressão e da criatividade, parece ter se transformado numa simples 
mercadoria que é produzida e reproduzida de forma mecânica para satisfazer o consumo de uma massa global.

\section{REFERÊNCIAS}

ADORNO, Theodor W. Dialética do Esclarescimento: fragmentos filosóficoa. Rio de Janeiro: Jorge Zahar Editor: 1985.

BAUMAN, Zygmunt. Comunidades: a busca por segurança na mundo atual. Rio de Janeiro: Jorge Zahar Editor: 2003.

Zahar Editor: 1999. Globalização: as consequências Humanas. Rio de Janeiro: Jorge

Modernidade Líquida. Rio de Janeiro: Jorge Zahar Editor, 2001.

CANCLINI, Néstor García. Culturas Híbridas: Estratégias para Entrar e Sair da Modernidade. 2ª ed. São Paulo: Editora da Universidade de São Paulo, 1998.

CASTELLS, Manuel. A Sociedade em Rede. 6a ed. São Paulo: Paz e Terra, 1999.

LÉVY, Pierre. Cibercultura. 3 ed. São Paulo: Editora 34, 2010.

LUSVARGHI, Luiza Cristina. MTV no Brasil - a padronização da cultura na mídia eletrônica mundial. São Paulo, 2002. 173f. Dissertação (Mestrado). Escola de Comunicação e artes da Universidade de São Paulo - Universidade de São Paulo. 2002.

HARVEY, David. Condição Pós-Moderna. 18o ed. São Paulo: Edições Loyola, 2009.

HALL, Stuart. A identidade cultural na pós-modernidade. 10 ed. Rio de Janeiro: DP\&A Editora, 2009.

OSTROWER, Fayga. Criatividade e Processos de Criação. 20 ed. Petrópolis: Editora Vozes, 1987. 